\title{
Can online exemplars trigger a spiral of silence? Examining the effects of exemplar opinions on perceptions of public opinion and speaking out
}

new media \& society 2017, Vol. 19(7) 1034-1051

(C) The Author(s) 2016

Reprints and permissions: sagepub.co.uk/journalsPermissions.nav DOI: I0.I I77/|46|4448|5625942 journals.sagepub.com/home/nms

\section{Thomas Zerback and Nayla Fawzi}

Ludwig-Maximilians-University Munich, Germany

\begin{abstract}
In modern media environments, social media have fundamentally altered the way how individual opinions find their way into the public sphere. We link spiral of silence theory to exemplification research and investigate the effects of online opinions on peoples' perceptions of public opinion and willingness to speak out. In an experiment, we can show that a relatively low number of online exemplars considerably influence perceived public support for the eviction of violent immigrants. Moreover, supporters of eviction were less willing to speak out on the issue online and offline when confronted with exemplars contradicting their opinion.
\end{abstract}

\section{Keywords}

Exemplification, hate speech, public opinion perception, spiral of silence online, user comments

After an Islamist took several hostages in a cafe in Sydney in December 2014, an Australian woman placed a hashtag on Twitter (\#illridewithyou) and offered to escort Muslims, who were planning to ride public busses in traditional clothing. Within a short period of time, thousands of Australians commented on the offer, most of them expressing their support for Muslim citizens and the initiative.

The incident is a good example of how today individual opinions rapidly spread into the public sphere where millions can read and comment on them. Not surprisingly, this

\section{Corresponding author:}

Thomas Zerback, Ludwig-Maximilians-University Munich, Oettingenstraße 67, Munich 81538, Germany.

Email: zerback@ifkw.Imu.de 
phenomenon has attracted the interest of communication scholars, who raise the question, if and how online opinions can affect individual perceptions of public opinion (Metzger, 2009; Schulz and Rössler, 2013). In other words, do people consider the views of other citizens voiced in social media as an indicator of what the public in general thinks about certain topics? And what are the behavioral consequences of these perceptions?

Perceptions of public opinion play a key role within the "spiral of silence" (NoelleNeumann, 1974). The theory assumes that peoples' willingness to speak out publicly on morally loaded issues depends on their perceptions of majority opinions in society. Perceiving public support for their own views will increase willingness to speak out, while perceiving themselves as part of the minority will cause them to fall silent (NoelleNeumann, 1974).

One source of public opinion perceptions communication researchers have discovered are exemplars. Exemplars are single events or persons depicted in the media that represent larger categories or groups. The exemplification approach basically tries to explain how such single cases influence individual attitudes and perceptions of reality (Zillmann and Brosius, 2000). Various empirical studies have shown that public opinion perceptions follow exemplar opinions presented in the media (Perry and Gonzenbach, 1997; Zillmann, 2002: 33).

The connection between exemplification theory and the spiral of silence is quite obvious: based on exemplar opinions, people may first form a picture of the climate of opinion regarding a certain issue and will then - depending on their own opinion - decide whether to speak out on the issue or not (Nekmat and Gonzenbach, 2013; Perry and Gonzenbach, 2000).

Exemplification theory and the spiral of silence were both developed in times when television and newspapers dominated the media landscape, which of course has undergone considerable changes until today. Social media like Facebook or Twitter have fundamentally altered the way how individual opinions reach a broader public where they can serve as cues to public opinion. Most importantly, the selection of single opinions and their public presentation no longer lies in the hands of journalists alone, but every user can voice his or her views via social media. Furthermore, the media and the personal social environment as the two main sources of public opinion perception in the spiral of silence have continuously converged (Schulz and Rössler, 2012). Social media enable social interaction and therefore feature attributes of interpersonal, private communication, and public mass communication. Therefore, many scholars have raised the question, if the key processes described by the spiral of silence and exemplification theory still apply to the modern media environment and computer-mediated communication (CMC) (Metzger, 2009; Schulz and Rössler, 2013).

It is the goal of the current study to address this question by experimentally analyzing the effects of exemplar opinions in an online discussion on perceptions of public opinion and willingness to speak out. Moreover, we investigate if the effects of online exemplars also extend into the offline world by comparing their influence on assessments of public opinion and willingness to speak out online and offline. In the theoretical part of the article, we introduce the key features of the spiral of silence and exemplification theory, relate them to each other, and discuss their applicability to online environments. In the empirical part, we present the results of an experiment where we manipulated the 
number and opinion of exemplars in an online discussion on the eviction of violent immigrants. The effects on public opinion perception and willingness to speak out online and offline are measured.

\section{The spiral of silence}

According to Noelle-Neumann, public opinion as a macro level phenomenon is the result of individual decisions to speak out publicly (see also Pan and McLeod, 1991). More precisely, she assumes that individuals who perceive their own opinion to be part of the minority tend to fall silent because they fear to become socially isolated and that those who coincide with the majority will show a greater willingness to express their opinion in public. However, the respective issue has to be controversial and morally loaded in order to exert social pressure (Noelle-Neumann and Petersen, 2004). To assess public opinion, individuals observe their environment - that is the mass media and their personal social surrounding - to get an impression of which opinions are socially accepted (Hayes et al., 2013; Noelle-Neumann, 1974; Noelle-Neumann and Petersen, 2004). Individual decisions to fall silent or to speak out in turn serve as public opinion cues for others resulting in an ongoing spiral process. Over time, one opinion grows stronger and becomes public opinion while others disappear because they cannot be expressed publicly without the risk of becoming socially isolated (Noelle-Neumann and Petersen, 2004).

Until today, single studies and meta-analyses (Glynn et al., 1997; Scheufele and Moy, 2000) have tested the theory, its central components and sub-processes (e.g. Hayes et al., 2013; Salmon and Neuwirth, 1990), its theoretical scope (e.g. Huang, 2005), as well as its shortcomings (Lasorsa, 1991) and confirmed the key assumptions. Critics have particularly stressed the fact that the mass media and the more general social environment may not be the only sources influencing the individual to speak out and have emphasized the role of reference groups (e.g. friends) (Glynn and Park, 1997) and groups of which individuals may not be a member ("the nebulous public") (Nekmat and Gonzenbach, 2013: 4). More recently, scholars also have asked if a spiral of silence can occur online where communication contexts differ from traditional settings in various ways (Schulz and Rössler, 2012).

\section{The spiral of silence online}

CMC challenges some of the key elements within the spiral of silence (McDevitt et al., 2003; Schulz and Rössler, 2012). Most importantly for this study, CMC offers additional sources that inform peoples' perception of public opinion. Online forums and social networks are places where single opinions on nearly every topic are frequently encountered (Walther and Jang, 2012), also because individuals can easily express their views there. Thus, in addition to opinions stemming from one's closer personal social environment or the media, also views from "nebulous," unknown groups gain visibility online. This is important because the online opinion environment can differ considerably from one's offline world in a way that opinions encountered online are likely to be more diverse (Schulz and Rössler, 2012). On the other hand, patterns of selective exposure might be 
more pronounced online and therefore restrict the diversity of viewpoints an individual may encounter (Garrett, 2009).

Aside from public opinion perception, willingness to speak out has also been rethought under CMC conditions. Some authors argue that the decreased visibility of social cues in CMC could lower the threshold to speak out publicly as discussants are physically isolated from each other (McDevitt et al., 2003: 457). The absence of non-verbal cues and the reduced impact of social status in CMC (Kiesler et al., 1984) might reduce the perceived likelihood and/or intensity of social sanctions compared to face-to-face contexts where other individuals are physically present (McDevitt et al., 2003). Thus, in an online environment, users may comment on issues even if they perceive themselves as part of the minority. However, they can still refrain from expressing their own opinion by posting irrelevant or unrelated comments. Therefore, McDevitt et al. (2003) proposed to distinguish between people "speaking out" that is taking an actual stand in a discussion and "speaking up" as merely commenting without expressing an opinion. This is important because speaking up cannot be interpreted as revealing one's own opinion to others. One could therefore question whether speaking up in online spaces that often are anonymous and lack social cues should rather be interpreted as a way of falling silent (Nekmat and Gonzenbach, 2013: 740).

Empirical studies that examined willingness to speaking out in online environments yield mixed results. Ho and McLeod (2008) observed that respondents were more willing to express their opinion online than offline. Nekmat and Gonzenbach (2013) compared different website sources (activist site vs news website) and did not find an influence on willingness to speak out online, but in line with spiral of silence theory showed that individuals were less likely to post comments when they saw themselves as part of the minority. Yun Woong and Park (2011) obtained similar results and additionally showed that people who were confronted with congruent postings were more likely to speak out online. However, no difference occurred between speaking out under anonymous and non-anonymous conditions. On the other hand, a survey by Pew Internet Research suggests that with regard to social media, those who feel that their network agrees with their position are more likely to join online conversations (Hampton et al., 2014: 23). ${ }^{1}$

Only few studies on the spiral of silence differentiate between speaking out and speaking up. Addressing this problem, McDevitt et al. (2003) analyzed real statements from an actual discussion on abortion and found that participants were rather speaking up than speaking out. However, other scholars who used a similar approach found a tendency to speak out online (Nekmat and Gonzenbach, 2013).

\section{Online exemplars as cues to public opinion}

How can online comments influence public opinion perceptions? Previous research has shown that an important source telling people how others think about certain topics are exemplars. Exemplars are defined as single events or persons that represent larger categories or groups. Because they share specific attributes with a group (e.g. "smoker") people tend to generalize other characteristics of the exemplar to the group as well (Zillmann, 2002: 22-23). Such generalizations can influence a wide range of judgments, 
for example, the perceived relevance of social problems (Gibson and Zillmann, 1994), probability estimates (Hoeken and Hustinx, 2009), risks (Aust and Zillmann, 1996), and also perceptions of public opinion (Daschmann, 2000; Perry and Gonzenbach, 1997; Zillmann and Brosius, 2000).

The cognitive mechanisms underlying the process of generalization are basically heuristic in nature. Zillmann (2002) assumes that people apply a representative heuristic by judging groups based on single persons they have encountered before and that this effect tends to intensify as the number of exemplars presented increases. From a theoretical point of view, two reasons apply to this reinforcement: the first explanation assumes that repeatedly encountered stimuli (e.g. opinions) create a larger number of instances that the individual can retrieve from memory (Wänke et al., 1995). Hence, judgments about the general frequency or likelihood of events are based on the number of cases remembered. The second explanation is called availability heuristic ${ }^{2}$ (Tversky and Kahneman, 1973) and attributes frequency judgments to the experienced ease of retrieval (Schwarz et al., 1991). The experience of eased retrieval in turn serves as a meta-cognition that guides frequency judgments (Alter and Oppenheimer, 2009). Empirical studies have shown that a repeated stimuli presentation increases retrieval ease (Higgins et al., 1985), an effect that also applies to media content (Busselle and Shrum, 2003) and repeatedly encountered opinions (Weaver et al., 2007).

More recently, scholars have also examined the role of online comments as exemplars $^{3}$ (Peter et al., 2014: 20; Schulz and Rössler, 2012: 350). Studies on the effects of user comments in news or social media have shown that they can influence the perceptions and behaviors of those who read them, for example, in the context of news recommendation ( $\mathrm{Li}$ et al., 2010) or product reviews (Chevalier and Mayzlin, 2006; Ye et al., 2011), especially when comment frequency is high (Duan et al., 2008; Park et al., 2007). Furthermore, these studies show that the valence of user comments affects evaluations of the content that the comments refer to (Shi et al., 2014; Walther et al., 2010). With regard to public opinion perceptions, results are rather scarce. Lee and Jang (2010) showed that readers of user comments contradicting news article slant perceived public opinion as more discrepant from the news position.

Regarding the influence of online exemplar presentation on public opinion perceptions, Schulz and Rössler (2012) further argue that opinions voiced in online environments do not necessarily translate into public opinion perceptions offline, because "individuals distinguish well enough between the online and the offline climate of opinion and behave differently depending on the environment they actually act in" (p. 360; see also Yun Woong and Park, 2011). In fact, exemplification theory suggests that the influence of exemplar presentations on peoples' perceptions of public opinion may differ depending on which population they have in mind - online users as a more specific group or the population in general. Zillmann and Brosius (2000) point out that exemplification effects rely on the similarity between the exemplar and the exemplified and that similarity in turn is a function of shared features between them (pp. 1-2). Their assumptions are based on earlier work by Tversky (1977), who states that if the degree of correspondence between an object being judged and the attributes of a class of objects stored in memory is sufficiently high, the matched object is considered a member of that class. Consequently, peoples' tendency to generalize from single exemplars to a larger class of 
people should be more pronounced when both are similar, that is, share more features. Thus, the effect of online exemplars should be stronger for online populations than the population in general, because of the greater similarity between the exemplars presented and the exemplified target population.

\section{Hypotheses and research questions}

Based on our theoretical remarks on exemplification, we expect online exemplars to influence the public opinion perceptions of those who encounter them:

H1. Perceptions of public opinion towards an issue will be positively correlated with the opinions of online exemplars towards that issue.

Moreover, as the accessibility of exemplar opinions increases when they are encountered more frequently we assume a reinforcing effect of exemplar frequency:

H1a. The effect of exemplar opinion on public opinion perceptions $(H 1)$ will be more pronounced when the number of exemplars voicing the same opinion increases (interaction effect).

The exemplars employed in our experimental design are Facebook users and therefore a visible part of the online population. Hence, the similarity between them and the online community is higher compared to the general population. We therefore predict a stronger influence of online exemplars on public opinion perceptions online compared to the general population:

H2. The effect of online exemplar opinions is more pronounced for assessments of the online climate of opinion than for assessments of public opinion in the general population.

In line with the central assumptions of the spiral of silence, we also assume an effect of online exemplar opinions on willingness to speak out:

H3. Willingness to speak out will decrease when online exemplar opinions and participants' personal opinion contradict each other compared to situations in which both coincide.

Following McDevitt et al. (2003), we will take a closer look on what users are saying, as commenting online does not necessary imply that they actually speak out:

$R Q 1$. Are participants in an online discussion on a morally loaded issue "speaking out" or "speaking up" in their comments?

$R Q 2$. Do exemplar opinions and personal opinions influence whether users are "speaking out" or "speaking up"? 
Table I. Experimental design and group sizes.

\begin{tabular}{lcc}
\hline $\begin{array}{l}\text { Factor I: Opinion } \\
\text { of exemplars }\end{array}$ & $\begin{array}{l}\text { Factor 2: Number } \\
\text { of exemplars }\end{array}$ & Group size $(N)$ \\
\hline Supporting eviction & 2 & 51 \\
Ambivalent opinion & 10 & 55 \\
Opposing eviction & 2 & 48 \\
Video only & 10 & 52 \\
\hline
\end{tabular}

\section{Method}

\section{Design and participants}

To test our hypotheses, we conducted an online experiment based on a $2 \times 3$ betweensubject design. A total of 364 participants were recruited from a German online access panel (Leiner, 2012) and randomly distributed across six experimental groups and one control group (see Table 1). On average, subjects were 32.9 years old (standard deviation $[S D]=12.9)$, just over half of them were female $(52.7 \%)$, and $52.2 \%$ had a higher formal education. There were no significant differences between the groups regarding education $\left(\chi^{2}(18, N=332)=14.46, p=.699\right)$, gender $\left(\chi^{2}(6, N=328)=8.10, p=.231\right)$, and age $(F(6$, $324)=0.47, p=.828)$.

\section{Procedure}

After a brief introduction, participants saw a short video clip ( 35 seconds) showing a young immigrant bullying a native German kid. Friends of the bully surrounded the scene and recorded videos with their mobile phones. After watching the video, participants were presented the actual stimulus, a Facebook discussion where a user had posted the clip and several other users serving as exemplars commented on the question whether violent immigrants should be evicted or not. The topic "eviction of violent immigrants" was chosen because of its strong moral loading which is regarded a main prerequisite in order to exert social pressure and to trigger spiral of silence processes (Noelle-Neumann and Petersen, 2004: 349).

The exemplar distribution differed systematically across the six treatment groups. As a first experimental factor, we varied the number of exemplars who commented on the video, which was either 2 or 10 . The second factor represented the opinion of the exemplars and participants either saw a discussion showing only people opposing the eviction of violent immigrants (contra eviction version), or a version with all exemplars favoring eviction (pro eviction version). In a third condition, pro and contra exemplars were mixed and equally distributed (ambivalent version). The control group received no exemplar information. After the stimulus presentation, the dependent and control variables were measured and participants were debriefed. 


\section{Measures}

Personal opinion. Personal opinion was measured before stimulus presentation. Respondents were asked to give their opinion on the eviction of violent immigrants using two items, each with a 5-point Likert scale ranging from 1 (totally disagree) to 5 (totally agree): "I think the eviction of violent immigrants is reasonable" and "Immigrants should be evicted when they commit violent acts." Both items strongly correlated $(r=.81, p<.001)$ and were therefore used to construct a mean index indicating participants' personal opinion on eviction $(M=3.02, S D=1.02, \alpha=.89)$. According to this index, participants were further categorized into two extreme groups, namely "opponents" (index values between 1 and 2.5; 41\% of the participants) and "supporters" (values between 3.5 and $5 ; 44 \%$ of the participants) of eviction. Those ranging in between were regarded as a third group with a less clear position (values between 2.6 and $3.4 ; 15 \%$ of the participants).

Moral loading of the issue. To assess whether the participants perceived the eviction of violent immigrants to be a morally loaded issue, we asked them the following question: "There are some topics that might be too touchy to discuss them in public. When you think about the 'eviction of violent immigrants' is that a touchy issue in your opinion or not?" To indicate their judgments, participants used a scroll bar ranging from 1 ("Not touchy at all") to 100 ("Very touchy") $(M=62.96 ; S D=28.40)$. The mean value differed significantly from the scale midpoint $(50)(t(340)=8.43, p<.001)$.

Climate of opinion estimates. Climate of opinion estimates were gathered for two target populations: first, participants assessed public opinion on the eviction issue within the general German population; after that they did the same for the more specific group of German Internet users. In both cases, participants estimated the share of the target population they assumed to favor the eviction of violent immigrants: "If you have to give a percentage estimate: How large is the share of Germans [German Internet users] supporting the eviction of violent immigrants?" $(M=54.02, S D=20.98),[M=51.72$, $S D=22.57]^{4}$

Willingness to speak out. We used two previously applied methods to capture the individual tendency to speak out in the online discussion presented: first, participants had to decide whether they wanted to post a comment in the Facebook discussion themselves (see also McDevitt et al., 2003; Nekmat and Gonzenbach, 2013; Yun Woong and Park, 2011): "Now you have the chance to post something in the group you just saw. Do you want to give a comment?" Respondents could answer on a 6-point scale ranging from 1 "I don't want to comment at all" to 6 "I really want to comment" $(M=3.62, S D=0.87)$. After this initial decision, those who agreed (indicating a value higher than 1) were forwarded to a text box implemented in the questionnaire where they could actually enter their comment freely. Comments could consist of several single statements. Following McDevitt et al. (2003) and Nekmat and Gonzenbach (2013), every statement was coded in terms of valence (5-point scale, $1=$ opposing the eviction of immigrants, $5=$ supporting the eviction of immigrants), object of reference (video, discussion, or no/other reference point) and 
content ("speaking out" vs "speaking up"). A total of 20 statements were randomly selected to perform a reliability test (Krippendorff's Alpha) and coded by the authors. Reliability scores were consistently satisfactory (valence: $\alpha=.732$, object of reference: $\alpha=.856$, speaking up/speaking out: $\alpha=.839$ ).

As a second measure of willingness to speak out, all participants were asked if they would like to join an offline discussion on the eviction of violent immigrants in the near future (Scheufele et al., 2001). Possible answers to that question were "Yes" (11.7\%), "Perhaps" (44.3\%), and "No" (44.0\%).

Treatment checks. Treatment checks were performed regarding the number and opinion of exemplars perceived. Participants first had to estimate how many people had commented on the video: "If you think of the Facebook discussion you just saw: Do you remember how many comments were beneath the video?" $(M=8.12, S D=7.11)$. Immediately afterwards they indicated if they perceived the comments to oppose or support the eviction of violent immigrants on a 7-point scale (1 "The comments opposed the eviction of violent immigrants" to 7 "The comments supported the eviction of violent immigrants") $(M=4.54, S D=0.89)$.

\section{Results}

\section{Treatment check}

According to the analysis of variance (ANOVA) results, all treatment checks were successful. Participants reproduced the actual number of exemplars presented beneath the video quite well. Those in the 2-exemplar condition indicated to have seen 3.37 $(S D=7.37)$ on average, those who received 10 exemplars $12.44(S D=6.87)$. The difference between both is statistically significant $\left(F(1,280)=50.36, p=.000, \eta^{2}=.27\right)$. The same applies to exemplar opinion: participants who saw exemplars supporting the eviction of violent immigrants $(M=6.87, S D=0.40)$, or opposing it $(M=1.68, S D=1.16)$, or who received an ambivalent opinion distribution $(M=4.77, S D=1.13)$, differed significantly in their judgments regarding the general tone of the exemplar opinions $(F(2$, 251) $=385.21, p=.000, \eta^{2}=.82$ ).

\section{Public opinion perceptions}

$H 1$ predicted that exemplar opinions would influence participants' perception of public opinion on the eviction of violent immigrants. Figure 1 shows the effects of both, the number and opinion of exemplars, on perceived public opinion in the general population and among the Internet users.

The number of exemplars $\left(F(1,321)=3.42, p=.066, \eta^{2}=.01\right)$ and the opinion they voiced in the online discussion $\left(F(2,321)=2.48, p=.086, \eta^{2}=.02\right)$ had no significant effects on the perception of public opinion within the larger population. Also, we could not observe an interaction effect between the two $\left(F(2,321)=2.49, p=.085, \eta^{2}=.02\right)$. However, the pattern shown in Figure 1 and the relatively high significance level indicate that participants at least somewhat aligned their judgments to the exemplar distribution 


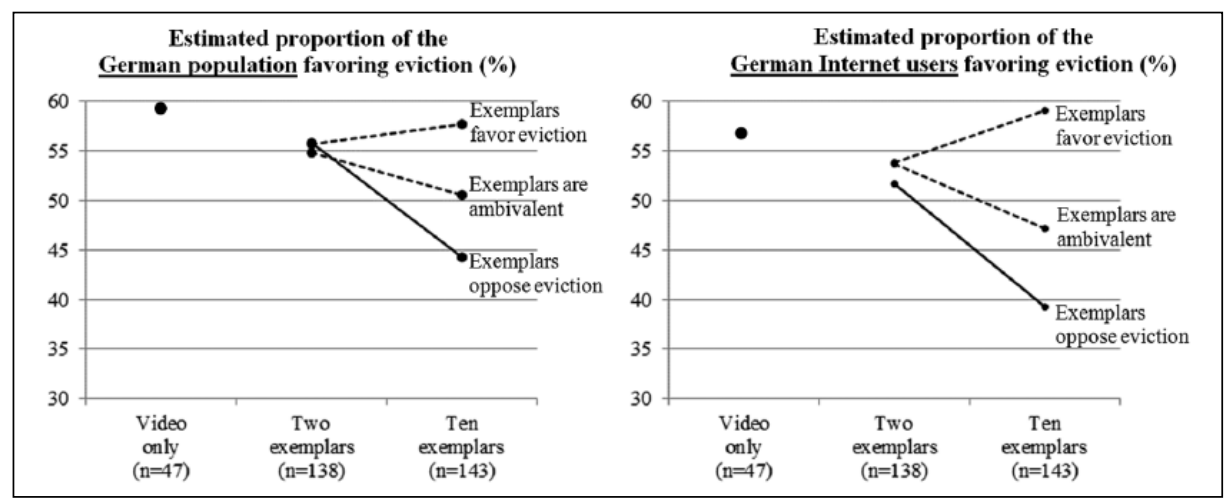

Figure I. Effects of exemplar distribution on public opinion perception.

presented. For instance, those who saw 10 exemplars supporting the eviction of violent immigrants $(57.8 \%)$ and those who received only opposing viewpoints $(44.3 \%)$ differed in their public opinion estimates by 13.5 percentage points. This difference proved to be statistically significant $\left(F(1,181)=4.91, p=.028, \eta^{2}=.03\right) .^{5}$

More pronounced effects are obtained when participants restricted their judgments to the Internet population. Still, the sheer number of exemplars commenting on eviction did not significantly influence climate of opinion estimates $(F(1,321)=3.05, p=.082$, $\left.\eta^{2}=.01\right)$, but exemplar opinion $\operatorname{did}\left(F(2,321)=5.80, p=.003, \eta^{2}=.04\right)$. An interaction pattern evolves when participants referred to Internet users $(F(2,321)=3.95, p=.020$, $\left.\eta^{2}=.02\right)$ : public opinion estimates of those confronted with a high number of eviction supporters $(59.1 \%)$ and of those who saw only opponents $(39.3 \%)$ now differed by almost 20 percentage points. We therefore find support for $H 1$ regarding the opinion distribution subjects perceived in the Internet population, however, not with regard to the general population. The interaction effect between exemplar opinion and exemplar frequency stated by Hla occurred for the Internet population and somewhat less (and not statistically significant) for the population in general. ${ }^{6}$ It should also be noted that participants who only saw the video (control condition) gave the highest estimates of support for eviction in the general population (59.6\%) and among the Internet users $(57.5 \%)$. We will get back to this result in the "Discussion" section.

$H 2$ assumed that the effects of exemplars are more pronounced for public opinion perception online compared to the general population. To test for such differences, we used a repeated measures ANOVA model including the two experimental factors (between-subject) and the two public opinion assessments (within-subject). Significant interactions between the experimental factors and the repeated measure indicate that the strength of exemplar effects differs regarding both populations. The differences between the main effects of exemplar frequency $(F(1,321)=0.00, p=.991)$, exemplar opinion $(F(1,321)=2.702, p=.069)$, and the interaction effects $(F(1,321)=1.309, p=.272)$ were not statistically significant. However, as the difference between the main effects of exemplar opinion is only slightly below a significant level, we conducted an additional analysis including only those participants who either saw exemplars against or in favor 
Table 2. Effects of exemplar/opinion congruence on willingness to speak out.

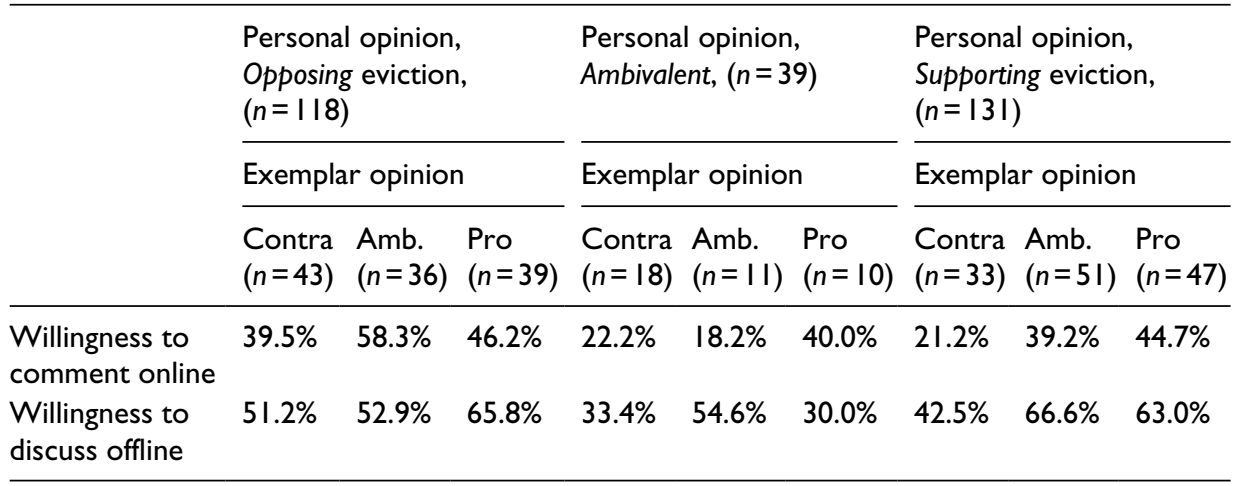

of eviction. In this case, the difference between the main effects of exemplar opinion turns out to be significant $(F(1,227)=5.198, p=.024)$, showing that homogeneous exemplars encountered online exert a stronger influence on peoples' assessments of public opinion online than on the population in general. ${ }^{7}$

\section{Willingness to speak out}

Our last analysis refers to participants' willingness to speak out when confronted with a discussion group supporting or opposing their personal view on eviction (H3). Table 2 shows the proportions of participants who either agreed to post a comment in the discussion group or declared that they were willing to take part in a forthcoming offline discussion on the eviction of violent immigrants.

The results show that the assumed silencing effect only occurred for those in favor of eviction: supporters who had the group majority on their side were twice as likely to post a comment (44.7\%) compared to those confronted with opposing comments $(21.2 \%)$ $\left(\chi^{2}(3, N=131)=4.84, p=.089\right)$. Participants initially opposing eviction showed almost equal levels of willingness to post online $\left(\chi^{2}(3, N=118)=2.82, p=.245\right)$ regardless of what exemplar opinion they were exposed to. In this case, those confronted with opposing views were even slightly more willing to comment online (46.2\%) than those perceiving supporting comments (39.5\%). A similar pattern can be observed regarding participants' willingness to discuss the topic offline: whereas $63.0 \%$ of eviction supporters who saw like-minded exemplars were willing to join the offline discussion ("yes," "perhaps"), only $42.5 \%$ of those who saw opposing comments $\operatorname{did} \operatorname{so}\left(\chi^{2}(3, N=130)=8.19\right.$, $p=.085)$. Again a somewhat reversed pattern evolved within the group of opponents, although again it did not reach statistical significance $\left(\chi^{2}(3, N=115)=4.87, p=.301\right){ }^{8}$ Therefore $H 3$ only finds support in the group of eviction supporters.

Going one step further, we analyzed what participants were posting to the discussion group in order to explore whether an individual actually expresses his or her view. We therefore content analyzed participants' comments and classified them according to the categories proposed by McDevitt et al. (2003). In total, most of the participants (61\%) preferred not to post a comment. A total of $89 \%(n=121)$ of those who were willing to 
post did indeed write something in the designated text box. On average the comments were 45 words in length and included 266 statements. The majority (65\%) of all comments opposed the eviction of immigrants, 7\% supported it, 9\% expressed a balanced opinion, and $19 \%$ expressed no valence.

Most comments contained speaking out statements (78\%), that is they took a position on the eviction of immigrants, while every fifth comment $(22 \%)$ included only statements without a position like experiences with this issue, facts on the video, or interactions with other group participants (speaking up; $R Q 1$ ).

Overall, opponents of eviction (48\%) were more likely to post a comment than supporters $(32 \%)$ and those with an ambivalent opinion (26\%). In more detail, $R Q 2$ asked whether speaking up or speaking out was influenced by one's own opinion in combination with exemplar opinion. The results show that participants who were opposing eviction did equally likely speak out, no matter if they were confronted with pro $(88.2 \%)$ or contra (86.7\%) exemplars. Only those who saw ambivalent opinions were less likely to speak out $(73.7 \%)$. Eviction supporters did more often speak out when the exemplars were in line with their opinion (78.9\%) than when they were ambivalent $(72.2 \%)$ and contra eviction (71.4\%). But differences were rather small.

\section{Discussion}

This study followed recent calls for testing spiral of silence mechanisms in an online environment as the online context may challenge key assumptions of the theory (Metzger, 2009; Schulz and Rössler, 2012). In this context, we considered the increasing prevalence of individual opinions in online social networks to be one important feature of modern media environments. Therefore, we linked exemplification and spiral of silence theory to explore exemplars' effects on public opinion perception and willingness to speak out. We could show that participants aligned their perceptions of public opinion towards the eviction of violent immigrants to the exemplar opinions they saw in a social network discussion. The effect was more pronounced when (1) the number of similar exemplars increased and when (2) subjects assessed public opinion among Internet users compared to the population in general. The first finding supports our assumption that frequently presented exemplars increase the cognitive accessibility of opinions and therefore their importance for public opinion judgments. The second result supports the assumption that people distinguish between online and offline climates of opinion in a way that their tendency to generalize from exemplar opinions depends on the target population they are judging.

Somewhat surprising, subjects in the control group who only saw the bullying video indicated levels of perceived public support for eviction that were as high as in the support condition. This result is most likely due to the negative valence of the video itself, which presented young immigrants as unfair, violent perpetrators. Watching the emotional, clearly negative pictures alone may have led to a higher level of perceived public support for eviction that could not be further increased by additional supporting exemplars. Otherwise, exemplars opposing eviction were able to lower perceptions of public support considerably. The high level of support for eviction in the control condition also points to the fact that the pure slant of media content alone can have considerable effects on public opinion estimates (e.g. Gunther, 1998). 
Participants' willingness to speak publicly was also influenced by the exemplar opinions: supporters of the eviction of violent immigrants were less likely to post a comment online and to take part in an offline discussion when they were confronted with exemplars contradicting their own opinion. Interestingly, the silencing effect did not occur among those opposing the eviction of violent immigrants. A possible reason for the different reactions might be that belonging to one of the two camps is associated with other characteristics influencing willingness to speak out independent from public opinion perceptions. Former research has shown that such individual level variables exist, for example, involvement, self-efficacy, news media use, attitude certainty (Glynn and Park, 1997; Lasorsa, 1991), a general willingness to self-censor (Hayes et al., 2005), or a generalized fear or anxiety to communicate with others (communication apprehension) (Neuwirth et al., 2007). Ho and McLeod (2008), for instance, who included two such variables (fear of isolation as a predisposition and communication apprehension) in their analyses of experimental data found that while controlling for them, the prospect of being confronted with incongruent opinions did not influence willingness to speak outneither in a CMC nor a F2F setting. Moreover, communication apprehension and fear of isolation exerted an independent negative effect on participants' willingness to speak out, and the effect of fear of isolation was considerably more pronounced in the F2F condition, whereas almost absent in the CMC setting. Their results support the assumption that in online environments some of the key variables within the spiral of silence may be less of importance - particularly the fear to become socially isolated. As the current study took place in an online environment as well, such possible alternative influences should be kept in mind when interpreting the results, although we were not able to determine their influence here. However, online environments might differ in the degree to which they actually represent an anonymous public (e.g. speaking out online in front of Facebook friends or in a forum with people unknown) and in the size of that public (a small online chat or a comment under a news article). Both aspects are important when it comes to speaking out in the sense of the spiral of silence, where effects should be greatest when one is confronted with a disagreeing small and anonymous public (Scheufele and Moy, 2000). Differentiating between the multifaceted online environments surely is an opportunity for future research. Finally, further content analysis of the actual comments revealed that most participants indeed voiced an opinion relating to the eviction of violent immigrants (speaking out).

\section{Limitations}

The results presented here need to be interpreted with caution for various reasons. First, limitations resulting from selective exposure need to be addressed. In modern media environments, people enjoy a great freedom to choose contents that reflect their own views and preferences, which is why some researchers have argued that under such circumstances encountering disagreement is not very likely (Garrett, 2009). However, a representative study conducted in the United States by Wojcieszak and Mutz (2009) shows that although people encounter more agreement than disagreement online, they still are regularly exposed to dissimilar views. Moreover, Knobloch-Westerwick et al. (2015) can show that compared to US citizens, the online search behavior of Germans is 
less prone to a confirmation bias (Knobloch-Westerwick et al., 2015). Finally, there are also situations where it is difficult to avoid dissimilar views entirely, especially when they dominate the public discourse (e.g. during scandals or social media firestorms).

Second, external validity is restricted because participants were aware of the experimental situation. Although we did not reveal the aim of the study, the attention they paid to the comments was probably higher than in an everyday situation. However, the fact that a great amount of participants actually posted serious comments regarding eviction demonstrates that the experimental setting was not perceived as being too artificial.

Third, one could argue that the video we presented exerted an effect on the perceptions of public opinion. This may be for two reasons. First, it may have functioned as an exemplar itself and increased perceived support for eviction. Although we cannot completely rule out this possibility, we assume that the comments did serve as the more relevant cue. While the video focuses on a direct experience with violent immigrants, the comments represent single opinions on the eviction of violent immigrants. Thus, the comments are more applicable to the public opinion estimations we asked the respondents to make. Second, as a consequence of watching this video clip subjects may have applied certain standards when they assessed public opinion afterwards-namely the standard of immigrant violence. Perhaps participants would have applied a different standard if the initial video had referred to another topic (e.g. immigrants getting attacked by native extremists). Examining the influence of such context factors online exemplars are embedded in is an interesting opportunity for future research.

A final constrain emerges from the issue we used as a stimulus. Although it fulfills the requirements proposed by Noelle-Neumann (Noelle-Neumann and Petersen, 2004), it also has the disadvantage that citizens are already familiar with it. The German media cover incidents of violence by immigrants on a regular basis. Consequently, our participants had at least a rough impression of what the public thinks about eviction. The fact that 10 exemplars nonetheless did have an effect is therefore worth considering and leads to the question what happens if new issues occur and people lack preexisting pictures of public opinion distributions. In such cases, online exemplar effects most likely will be even stronger.

We think that in the future, field studies should tie up to the remarks above and complement experimental examinations. For instance, combinations of content analyses and surveys could concentrate on the dynamic nature of online opinion environments and public opinion perceptions. Also, the cognitive processes involved in public opinion assessments within different populations would be an interesting field for future research. In this context, think aloud techniques or qualitative interviews (e.g. Shamir, 1995) would allow researchers to identify the criteria individuals apply when generalizing from exemplars to varying populations.

\section{Funding}

The author(s) received no financial support for the research, authorship, and/or publication of this article.

\section{Notes}

1. Encountering disagreement can also increase willingness to speak out. Rojas (2010) assumes that people who are confronted with opposing viewpoints may take "corrective actions" to 
ensure that their views are heard in the public sphere. However, empirical studies that confirmed the tendency for corrective actions (Barnidge and Rojas, 2014; Rojas, 2010) do not consider the moral loading as a decisive aspect of the issue at hand. Also they did not provide for an actual possibility to speak out, but respondents were asked how frequently they talk with people holding different political opinions.

2. Although most exemplification studies refer to the availability heuristic (e.g. Zillmann and Brosius, 2000), some also draw attention to the importance of the distinction between availability and accessibility (e.g. Gibson and Zillmann, 1994), because information that is available in memory might still be not equally accessible. The effects of exemplar frequency we examine in the current study are primarily based on increased cognitive accessibility of frequently presented exemplar information.

3. Scholars have also discussed if such comments can be regarded as exemplars (Peter et al., 2014: 20; Schulz and Rössler, 2012: 350). Following the understanding of Zillmann and Brosius (2000) outlined above, single cases obtain the status of exemplification, regardless of the context they are embedded in, because of a "deep-rooted inclination to generalize observed phenomena" (p. 11). This includes online comments and opens exemplification research also to online discussions (Peter et al., 2014; Ziegele and Weber, 2015).

4. According to a representative survey among German citizens in $2010,68 \%$ of the population favored the eviction of immigrants "who have been convicted of serious crimes, welfare fraud, or illegal employment" (Focus, 2010). The fact that our sample consists of less proponents of eviction (44\%, those participants indicating a value higher than 3.5 on the personal opinion scale) is probably partly due to differences in question wording in the representative study, which included more possible and severe reasons for eviction, and the non-representative nature of our sample.

5. To test the difference between the two groups, we performed an additional analysis of variance (ANOVA) including only the pro and contra exemplar condition and tested the interaction effect between exemplar number and opinion.

6. The effect of exemplars persists even when participants' personal opinion about eviction is controlled for.

7. Additional post-hoc tests also revealed that the effect of exemplar opinion that occurred in the 10-exemplar condition was mainly due to the influence of those exemplars opposing eviction. Post-hoc tests (S-N-K) were employed to test for differences between the 2- and 10-exemplar conditions. Due to non-significant differences between the three 2-exemplar conditions $(F(135,2)=0.035, p=.966)$ and the population in general $(F(135,2)=0.131, p=.877)$, they were treated as one group. Regarding both types of public opinion perceptions, a significant difference between the combined "two-exemplar group" and the group with 10 opposing exemplars was observed $(p<.05)$.

8. Because only few participants $(N=39)$ had an ambivalent opinion on the eviction of violent immigrants, we refrain from interpreting the according shares within the subgroups.

\section{References}

Alter AL and Oppenheimer DM (2009) Uniting the tribes of fluency to form a metacognitive nation. Personality and Social Psychology Review 13(3): 219-235.

Aust CF and Zillmann D (1996) Effects of victim exemplification in television news on viewer perception of social issues. Journalism \& Mass Communication Quarterly 73(4): 787-803.

Barnidge M and Rojas H (2014) Hostile media perceptions, presumed media influence, and political talk: expanding the corrective action hypothesis. International Journal of Public Opinion Research 26(2): 135-156. 
Busselle RW and Shrum LJ (2003) Media exposure and exemplar accessibility. Media Psychology 5(3): 255-282.

Chevalier JA and Mayzlin D (2006) The effect of word of mouth on sales: online book reviews. Journal of Marketing Research 43(3): 345-354.

Daschmann G (2000) Vox pop \& vox polls: the impact of poll results and voter statements in the media on the perception of a climate of opinion. International Journal of Public Opinion Research 12(2): 160-181.

Duan W, Gu B and Whinston AB (2008) Do online reviews matter? An empirical investigation of panel data. Decision Support Systems 45(4): 1007-1016.

Focus (2010) Sollen Ausländer, die wegen Schwerverbrechen, Sozialhilfebetrug oder Schwarzarbeit verurteilt wurden, automatisch aus Deutschland abgeschoben werden? (Should foreigners who have been convicted on serious crime, welfare fraud or illegal work, automatically be evicted from Germany?) In: Statista. Available at: http://de.statista.com (accessed 20 June 2015).

Garrett RK (2009) Echo chambers online? Politically motivated selective exposure among Internet news users. Journal of Computer-Mediated Communication 14(2): 265-285.

Gibson R and Zillmann D (1994) Exaggerated versus representative exemplification in news reports: perception of issues and personal consequences. Communication Research 21(5): 603-624.

Glynn CJ and Park E (1997) Reference groups, opinion intensity, and public opinion expression. International Journal of Public Opinion Research 9(3): 213-232.

Glynn CJ, Hayes AF and Shanahan J (1997) Perceived support for one's opinions and willingness to speak out. Public Opinion Quarterly 61(3): 452-463.

Gunther AC (1998) The persuasive press inference: effects of mass media on perceived public opinion. Communication Research 25(5): 486-504.

Hampton KN, Rainie L, Lu W, et al. (2014) Social Media and The "Spiral of Silence." Washington, DC: Pew Research Center.

Hayes AF, Glynn C and Shanahan J (2005) Willingness to self-censor: a construct and measurement tool for public opinion research. International Journal of Public Opinion Research 17(3): 298-323.

Hayes AF, Matthes J and Eveland WP (2013) Stimulating the quasi-statistical organ: fear of social isolation motivates the quest for knowledge of the opinion climate. Communication Research 40(4): 439-462.

Higgins ET, Bargh JA and Lombardi WJ (1985) Nature of priming effects on categorization. Journal of Experimental Psychology: Learning, Memory, and Cognition 11(1): 59-69.

Hoeken H and Hustinx L (2009) When is statistical evidence superior to anecdotal evidence in supporting probability claims? The role of argument type. Human Communication Research 35(4): 491-510.

Ho SS and McLeod DM (2008) Social-psychological influences on opinion expression in faceto-face and computer-mediated communication. Communication Research 35(2): 190-207.

Huang H (2005) A cross-cultural test of the spiral of silence. International Journal of Public Opinion Research 17(3): 324-345.

Kiesler S, Siegel J and McGuire TW (1984) Social psychological aspects of computer-mediated communication. American Psychologist 39(10): 1123-1134.

Knobloch-Westerwick S, Mothes C, Johnson BK, et al. (2015) Political online information searching in Germany and the United States: confirmation bias, source credibility, and attitude impacts. Journal of Communication 65(3): 489-511.

Lasorsa DL (1991) Political outspokenness: factors working against the spiral of silence. Journalism \& Mass Communication Quarterly 68(1-2): 131-140. 
Lee E and Jang YJ (2010) What do others' reactions to news on internet portal sites tell us? Effects of presentation format and readers' need for cognition on reality perception. Communication Research 37(6): 825-846.

Leiner DJ (2012) SoSci Panel: the noncommercial online access panel. Mannheim. Available at: https://www.soscisurvey.de/panel/download/SoSciPanel.GOR2012.pdf

Li Q, Wang J, Chen YP, et al. (2010) User comments for news recommendation in forum-based social media. Information Sciences 180(24): 4929-4939.

McDevitt M, Kiousis S and Wahl-Jorgensen K (2003) Spiral of moderation: opinion expression in computer-mediated discussion. International Journal of Public Opinion Research 15(4): 454-470.

Metzger MJ (2009) The study of media effects in the era of internet communication. In: Nabi RL and Oliver MB (eds) The SAGE Handbook of Media Processes and Effects. Los Angeles, CA: SAGE, pp. 561-576.

Nekmat E and Gonzenbach WJ (2013) Multiple opinion climates in online forums: role of website source reference and within-forum opinion congruency. Journalism \& Mass Communication Quarterly 90(4): 736-756.

Neuwirth K, Frederick E and Mayo C (2007) The spiral of silence and fear of isolation. Journal of Communication 57(3): 450-468.

Noelle-Neumann E (1974) The spiral of silence: a theory of public opinion. Journal of Communication 24(2): 43-51.

Noelle-Neumann E and Petersen T (2004) The spiral of silence and the social nature of man. In: Kaid LL (ed.) Handbook of Political Communication Research. Mahwah, NJ: Lawrence Erlbaum Associates, pp. 339-356.

Pan Z and McLeod JM (1991) Multilevel analysis in mass communication research. Communication Research 18(2): 140-173.

Park D, Lee J and Han I (2007) The effect of on-line consumer reviews on consumer purchasing intention: the moderating role of involvement. International Journal of Electronic Commerce 11(4): 125-148.

Perry SD and Gonzenbach WJ (1997) Effects of news exemplification extended: considerations of controversiality and perceived future opinion. Journal of Broadcasting \& Electronic Media 41(2): 229-244.

Perry SD and Gonzenbach WJ (2000) Inhibiting speech through exemplar distribution: can we predict a spiral of silence? Journal of Broadcasting \& Electronic Media 44(2): 268-281.

Peter C, Rossmann C and Keyling T (2014) Exemplification 2.0. Journal of Media Psychology: Theories, Methods, and Applications 26(1): 19-28.

Rojas H (2010) "Corrective" actions in the public sphere: how perceptions of media and media effects shape political behaviors. International Journal of Public Opinion Research 22(3): 343-363.

Salmon CT and Neuwirth K (1990) Perceptions of opinion "climates" and willingness to discuss the issue of abortion. Journalism \& Mass Communication Quarterly 67(3): 567-577.

Scheufele DA and Moy P (2000) Twenty-five years of the spiral of silence: a conceptual review and empirical outlook. International Journal of Public Opinion Research 12(1): 3-28.

Scheufele DA, Shanahan J and Eunjung L (2001) Real talk: manipulating the dependent variable in spiral of silence research. Communication Research 28(3): 304-324.

Schulz A and Rössler P (2012) The spiral of silence and the internet: selection of online content and the perception of the public opinion climate in computer-mediated communication environments. International Journal of Public Opinion Research 24(3): 346-367.

Schulz A and Rössler P (2013) Schweigespirale Online. Die Theorie der öffentlichen Meinung und das Internet. Baden-Baden: Nomos. 
Schwarz N, Bless H, Strack F, et al. (1991) Ease of retrieval as information: another look at the availability heuristic. Journal of Personality and Social Psychology 61(2): 195-202.

Shamir J (1995) Information cues and indicators of the climate of opinion: the spiral of silence theory in the Intifada. Communication Research 22(2): 24-53.

Shi R, Messaris P and Cappella JN (2014) Effects of online comments on smokers' perception of antismoking public service announcements. Journal of Computer-Mediated Communication 19(4): 975-990.

Tversky A (1977) Features of similarity. Psychological Review 84(4): 327-352.

Tversky A and Kahneman D (1973) Availability: a heuristic for judging frequency and probability. Cognitive Psychology 5(2): 207-232.

Walther JB, DeAndrea D, Kim J, et al. (2010) The influence of online comments on perceptions of antimarijuana public service announcements on YouTube. Human Communication Research 36(4): 469-492.

Walther JB and Jang J (2012) Communication processes in participatory websites. Journal of Computer-Mediated Communication 18(1): 2-15.

Wänke M, Schwarz N and Bless H (1995) The availability heuristic revisited: experienced ease of retrieval in mundane frequency estimates. Acta Psychologica 89(1): 83-90.

Weaver K, Garcia SM, Schwarz N, et al. (2007) Inferring the popularity of an opinion from its familiarity: a repetitive voice can sound like a chorus. Journal of Personality and Social Psychology 92(5): 821-833.

Wojcieszak ME and Mutz DC (2009) Online groups and political discourse: do online discussion spaces facilitate exposure to political disagreement? Journal of Communication 59(1): 40-56.

Ye Q, Law R, Gu B, et al. (2011) The influence of user-generated content on traveler behavior: an empirical investigation on the effects of e-word-of-mouth to hotel online bookings. Computers in Human Behavior 27(2): 634-639.

Yun Woong G and Park S (2011) Selective posting: willingness to post a message online. Journal of Computer-Mediated Communication 16(2): 201-227.

Ziegele M and Weber M (2015) Example, please! Comparing the effects of single customer reviews and aggregate review scores on online shoppers' product evaluations. Journal of Consumer Behavior 14(2): 103-114.

Zillmann D (2002) Exemplification theory of media influence. In: Bryant J and Zillmann D (eds) Media Effects: Advances in Theory and Research. Mahwah, NJ; London: Lawrence Erlbaum Associates, pp. 19-41.

Zillmann D and Brosius H (2000) Exemplification in Communication: The Influence of Case Reports on the Perception of Issues. Mahwah, NJ: Lawrence Erlbaum Associates.

\section{Author biographies}

Thomas Zerback is a postdoctoral researcher at the Department of Communication Studies and Media Research at Ludwig-Maximilians-University Munich, Germany. His research focuses on political communication, public opinion perception, and media diversity.

Nayla Fawzi is a postdoctoral researcher at the Department of Communication Studies and Media Research at Ludwig-Maximilians-University Munich, Germany. Her research focuses on the mediatization of politics, political socialization, and cyberbullying. 